\title{
ANÁLISE ESTRUTURAL DE UM REMANESCENTE DE CAATINGA NO SERIDÓ PARAIBANO
}

\author{
Juliano Ricardo Fabricante ${ }^{*}$ \& Leonaldo Alves de Andrade ${ }^{2}$ \\ ${ }^{1}$ Doutorando em Agronomia (Ecologia Vegetal e Meio Ambiente), UFPB, CCA, PPGA, Lab. de Ecologia Vegetal, CEP: 58397-000, Areia, PB. \\ 2 Prof $^{\circ}$ Associado, D. Sc. UFPB, CCA, DF, Laboratório de Ecologia Vegetal, CEP: 58397-000, Areia, PB. \\ *E-mail: julianofabricante@ig.com.br
}

\section{RESUMO}

Embora seja um dos biomas brasileiros mais heterogêneos e menos conhecidos a savana estépica, ou caatinga, encontra-se sob forte antropismo. O presente trabalho teve como objetivos caracterizar a composição florística e a estrutura da vegetação arbustivo-arbórea de um remanescente de savana estépica arborizada no município de Santa Luzia. Na Fazenda Madalena (6 $6^{\circ} 48^{\prime} 36,7^{\prime}$ 'S e $\left.36^{\circ} 57^{\prime} 38,8^{\prime \prime} \mathrm{W}\right)$ foi efetuado um levantamento florístico e fitossociológico em 20 parcelas totalizando $4.000 \mathrm{~m}^{2}$ de área amostrada. Analisou-se a estrutura dos estratos adulto e regenerante e a diversidade da comunidade. Foram amostrados 2.368 indivíduos, pertencentes a oito famílias, 15 gêneros e 22 espécies, onde as famílias Fabaceae e Euphorbiaceae e as espécies Croton sonderianus Müll. Arg., Caesalpinia pyramidalis Tul., Pilosocereus gounellei (F.A.C. Weber) Byles \& G.D. Rowley, Jatropha mollissima (Pohl) Baill., Cnidoscolus phyllacanthus (Müll. Arg.) Pax \& L. Hoffm. foram as mais representativas. Analisando-se a distribuição diamétrica, a distribuição hipsométrica e a diversidade, constatou-se um padrão de vegetação mais pobre do que aqueles encontrados na maioria das fitofisionomias de caatinga.

Palavras-chave: Fitodiversidade, Caatinga, microrregião do Seridó.

\section{ABSTRACT}

STRUCTURAL ANALYSIS OF A FRAGMENT OF CAATINGA IN THE SERIDÓ REGION OF PARAÍBA. The caatinga or esteppic savanna, is one of the more heterogeneous and unknown Brazilian biome, being under high antropic pressure. The present work aimed to study the floristic composition and the structure of the shrub-tree stratum in a fragment of caatinga, in Santa Luzia Municipality, Seridó micro region in Paraíba State. Seridó is one of de priority spot for biodiversity conservation in the semi-arid tropic. The research took place at the Madalena Farm (6 $6^{\circ} 48^{\prime} 36.7^{\prime \prime} S$ and $36^{\circ} 57^{\prime} 38.8^{\prime \prime} \mathrm{W}$ ), being accomplished a survey in 20 parcels which totalize $4,000 \mathrm{~m}^{2}$ of sampled area. The structure of the adult and the natural regeneration strata, as well the vegetation diversity was analyzed. Were surveyed 2,368 individuals, belonging to eight families, 15 genera and 22 species. The families Fabaceae and Euphorbiaceae, and the species Croton sonderianus Müll. Arg., Caesalpinia pyramidalis Tul., Pilosocereus gounellei (F.A.C. Weber) Byles \& G.D. Rowley, Jatropha mollissima (Pohl) Baill. and Cnidoscolus phyllacanthus (Müll. Arg.) Pax \& K. Hoffm. were the most representative. By the analyses of vegetation diversity, diametric and hypsometric distribution it was find out to be a very poor vegetation stand, comparing to others caatinga physiognomies.

Keywords: Phytodiversity, Caatinga, Seridó Micro region.

\section{INTRODUÇÃO}

Distribuindo-se pelos Estados do Piauí, Ceará, Rio Grande do Norte, Paraíba, Pernambuco, Alagoas, Sergipe, e Bahia e em parte do Estado de Minas Gerais (MMA 2002), o bioma caatinga é considerado uma das 37 grandes regiões geográficas do planeta (Aguiar et al. 2002), possuindo a vegetação mais heterogênea dentre os biomas brasileiros (Engler 1951, Rizzini
1997, Araújo \& Martins 1999). Conforme AndradeLima (1981) são reconhecidas 12 tipologias diferentes de caatinga.

Abrangendo uma área de aproximadamente $734.478 \mathrm{~km}^{2}$, a caatinga ou savana estépica é considerada um dos biomas brasileiros menos conhecidos, razão por que, sua diversidade biológica tem sido subestimada (MMA 2002). Segundo Tabarelli et al. (2000), somente $41 \%$ da caatinga foram amostrados 
e boa parte ainda é considerada, sub-amostrada. Não obstante esta situação, cerca de $70 \%$ da caatinga ainda está submetida ao antropismo em algum grau e, as áreas com extrema antropização correspondem a 35,3\% do bioma (MMA 2002). Diante desta realidade, o conhecimento e a conservação do referido bioma se tornam urgentes e de grande importância, particularmente nas áreas menos estudadas (Albuquerque \& Andrade 2001, Leal et al. 2003).

Localizado no rebordo ocidental do Planalto da Borborema, o Seridó Ocidental Paraibano apresenta feições das caatingas hipo e hiperxerófilas, cujos componentes predominantes são árvores e arbustos com dominância de poucas espécies e um estrato herbáceo efêmero. De acordo com a classificação proposta por Andrade et al. (1999a, 1999b), a província enquadra-se em uma região ecológica que apresenta temperaturas mínimas que variam de 15,15 a $25,69^{\circ} \mathrm{C}$ e máxima próxima de $33^{\circ} \mathrm{C}$, com amplitude térmica de $21,91^{\circ} \mathrm{C}$. A precipitação média anual é de $569 \mathrm{~mm}$ com déficit hídrico variando de oito a 12 meses no ano. Os valores médios dos índices de aridez e umidade efetiva para esta região, são de 60,13 e -59,77, respectivamente. Segundo o sistema de classificação climática de Thornthwaite, o clima desta região é DA'da', ou seja, semi-árido, megatérmico, com excedente hídrico pequeno ou nulo e com concentração da evapotranspiração nos meses de verão igual a 29\%, atingindo uma média anual de $1.464 \mathrm{~mm}$. Os solos são predominantemente jovens, arenosos, com presença de afloramentos graníticos (IBGE 2006). Segundo MMA (2002) o Seridó Paraibano constitui uma das áreas prioritárias para conservação da caatinga.

O presente trabalho teve como objetivos caracterizar a composição florística e a estrutura da vegetação arbustivo-arbórea de uma área de savana estépica arborizada no município de Santa Luzia, Seridó Ocidental Paraibano.

\section{MATERIAL E MÉTODOS}

\section{LOCAL DE ESTUDO}

Localizada no Município de Santa Luzia, Seridó Ocidental Paraibano, a Fazenda Madalena situase nas coordenadas geográficas de $6^{\circ} 48^{\prime} 36,7^{\prime} \mathrm{S}$ e $36^{\circ} 57^{\prime} 38,8^{\prime}$ 'W , está a uma altitude média de $271 \mathrm{~m}$ e possui área aproximada de 2.000 hectares. Segundo histórico de uso realizado durante este trabalho, o remanescente estudado não sofre corte raso desde 1964; a partir de então, o que tem acontecido são cortes seletivos para retirada de estacas e lenha, mantendo a vegetação nas fases inicial e intermediária de sucessão ecológica. A área é também é explorada com criação de gado bovino e caprino.

\section{PROCEDIMENTOS METODOLÓGICOS}

Usando-se a metodologia desenvolvida para o bioma caatinga (Rodal et al. 1992), foi efetuado um levantamento florístico e fitossociológico em 20 parcelas com área de $200 \mathrm{~m}^{2}$ cada uma. Os indivíduos inseridos nas unidades amostrais foram identificados e tomados o DNS (diâmetro ao nível do solo) e a altura total, utilizando-se suta dendrométrica e vara telescópica graduada. Os indivíduos foram enquadrados em dois estádios ontogenéticos: adultos e regenerantes. Foram considerados regenerantes todos os indivíduos que apresentaram DNS inferior a três $\mathrm{cm}$, independentemente da altura.

Para o estrato adulto, analisou-se a área basal e os valores relativos e absolutos de Freqüência, Densidade, Dominância, o Valor de Cobertura (VC) e o Valor de Importância (VI) (Brown-Blanquet 1950, Müller-Dombois \& Ellemberg 1974, Mateucci \& Colma 1982, Whittaker 1984). Para a regeneração natural foram utilizados os descritores Densidade, Freqüência, Classes de Tamanho da Regeneração Natural nas suas formas absoluta e relativa, e o Índice de Regeneração Natural (Lamprecht 1964, Scolforo et al. 1998, Kent \& Coker 1999). Os regenerantes foram divididos em quatro categorias: Classe I - indivíduos com altura $>0,10$ e $<0,30 \mathrm{~m}$; Classe II - indivíduos com altura $>0,30$ e $<1,50 \mathrm{~m}$; Classe III - indivíduos com altura $\geq 1,5$ e $<3,0 \mathrm{~m}$ e Classe IV - indivíduos com altura $>3,0 \mathrm{~m}$ e DNS $<3 \mathrm{~cm}$.

O DNS e a altura dos espécimes amostrados foram distribuídos em frequiências com intervalos de $3 \mathrm{~cm}$ para o DNS e 1m para a altura. As inferências sobre as taxas de recrutamento e mortalidade na comunidade foram feitas pelo Quociente "q" de De Liocourt (Wadsworth 2000).

Para avaliar a diversidade da área foi calculado o Índice de Diversidade de Shannon-Weaver (H') (Ricklefs 1996) e a eqüitabilidade, através do índice de Pielou (E) (Odum 1988). 
A lista florística gerada foi organizada de acordo com o Sistema APG II (2003) e a lista dos autores das espécies segundo Brummitt \& Powell (1992).

As análises estastísticas foram feitas utilizando-se o Software Mata Nativa $($.

\section{RESULTADOS E DISCUSSÃO}

Foram amostrados 2.368 indivíduos, pertencentes a oito famílias, 15 gêneros e 22 espécies. Deste montante, 1.252 indivíduos, 20 espécies, 15 gêneros e oito famílias no estrato adulto e 1.129 espécimes, 15 espécies, 12 gêneros e sete famílias na regeneração natural (Tabela I).

As famílias Fabaceae e Euphorbiaceae foram as mais representativas na área estudada. Fabaceae apresentou seis espécies e Euphorbiaceae três, totalizando $42,85 \%$ dos táxons. Das demais famílias, Anacardiaceae foi a única que apresentou mais de uma espécie.

Estas famílias têm demonstrado uma alta representatividade em levantamentos feitos em diferentes tipologias da caatinga (Tavares et al. 1975, Figueiredo 1987, Araújo et al. 1995, Oliveira et al. 1997, Ferraz et al. 1998, Pereira et al. 2001, Pereira et al. 2002, Lemos \& Rodal 2002, Rodal \& Nascimento 2002, Amorim et al. 2005, Andrade et al. 2005).

A espécie mais abundante foi Croton sonderianus com 786 indivíduos, respondendo por 33,11\% do total amostrado. Dentre esses, 247 adultos e 539 regenerentes. A segunda espécie em número de indivíduos foi Caesalpinia pyramidalis; foram amostrados 457

Tabela I. Lista das famílias, espécies* e respectivos estádios ontogenéticos. Dados da Fazenda Madalena, Município de Santa Luzia, PB.

\begin{tabular}{|c|c|c|}
\hline Famílias/Espécies & Nome vulgar & EO \\
\hline \multicolumn{3}{|l|}{ Anacardiaceae } \\
\hline Myracrodruon urundeuva Allemão & Aroeira & A e R \\
\hline Spondias tuberosa Arruda & Umbuzeiro & A \\
\hline \multicolumn{3}{|l|}{ Apocynaceae } \\
\hline Aspidosperma pyrifolium Mart. & Pereiro & A e $R$ \\
\hline \multicolumn{3}{|l|}{ Burseraceae } \\
\hline Commiphora leptophloeos (Mart.) J.B. Gillett & Umburana & A e $R$ \\
\hline \multicolumn{3}{|l|}{ Cactaceae } \\
\hline Pilosocereus gounellei (F.A.C. Weber) Byles \& G.D. Rowley & Xique-xique & A e R \\
\hline \multicolumn{3}{|l|}{ Cochlospermaceae } \\
\hline Cochlospermum cf. vitifolium (Willd.) Spreng. & Algodão bravo & A \\
\hline \multicolumn{3}{|l|}{ Combretaceae } \\
\hline Combretum leprosum Mart. & Mofumbo & A e R \\
\hline \multicolumn{3}{|l|}{ Euphorbiaceae } \\
\hline Cnidoscolus phyllacanthus (Müll. Arg.) Pax \& K. Hoffm. & Favela & A e R \\
\hline Croton sonderianus Müll. Arg. & Marmeleiro & A e R \\
\hline Jatropha mollissima (Pohl) Baill. & Pinhão & A e R \\
\hline \multicolumn{3}{|l|}{ Fabaceae } \\
\hline Anadenanthera macrocarpa (Benth.) Brenan & Angico & A e R \\
\hline Bauhinia cheilantha (Bong.) Steud. & Mororó & A \\
\hline Caesalpinia pyramidalis Tul. & Catingueira & A e R \\
\hline Mimosa adenophylla Taub. & Jurema amorosa & A e $R$ \\
\hline Mimosa tenuiflora (Willd.) Poir. & Jurema preta & A e R \\
\hline Piptadenia stipulacea (Benth.) Ducke & Jurema branca & A e R \\
\hline
\end{tabular}

EO - Estádio Ontogenético; A - Adulto; R -Rregenerante.

* Foram amostradas cinco morfoespécies. 
espécimes, dentre eles 231 adultos e 226 regenerantes. Outros três táxons contribuíram de forma expressiva: Pilosocereus gounellei, Jatropha mollissima e Cnidoscolus phyllacanthus; somadas às anteriormente citadas, foram responsáveis por mais de $75 \%$ do total de espécimes amostrados (Tabelas II e III).

As espécies que apresentaram as populações mais expressivas foram aquelas típicas de ambientes perturbados. Pereira et. al. (2002), Drumond et al. (2002), Alcoforado-Filho et al. (2003) e Andrade et al. (2005), obtiveram resultados semelhantes, indicando a maior abundância de alguns destes táxons, nas áreas mais antropizadas das caatingas (Ferreira 1988, Sampaio 1996, Sampaio et al. 1998, Pereira et al. 2001), o que corrobora com as condições de conservação observadas no local.

A espécie com maior VI foi Cnidoscolus phyllacanthus (Tabela II). Tal resultado se deve, sobretudo, à grande dominância que a espécie apresentou: 8,565 $\mathrm{m}^{2} \mathrm{ha}^{-1}$, representando 37,66\% do total para a área. Por apresentar madeira de baixa densidade, a espécie não é explorada na área, permitindo desta forma, seu desenvolvimento superior ao das demais espécies.

Caesalpinia pyramidalis, Pilosocereus gounellei, Croton sonderianus e Jatropha mollissima também apresentaram valores de VI significativos, principalmente por deterem grande número de indivíduos, o que se refletiu sobre a estrutura.

Dentre os regenerantes Croton sonderianus foi o mais expressivo (Tabela III). A espécie foi a única representada em todas as unidades amostrais e a mais

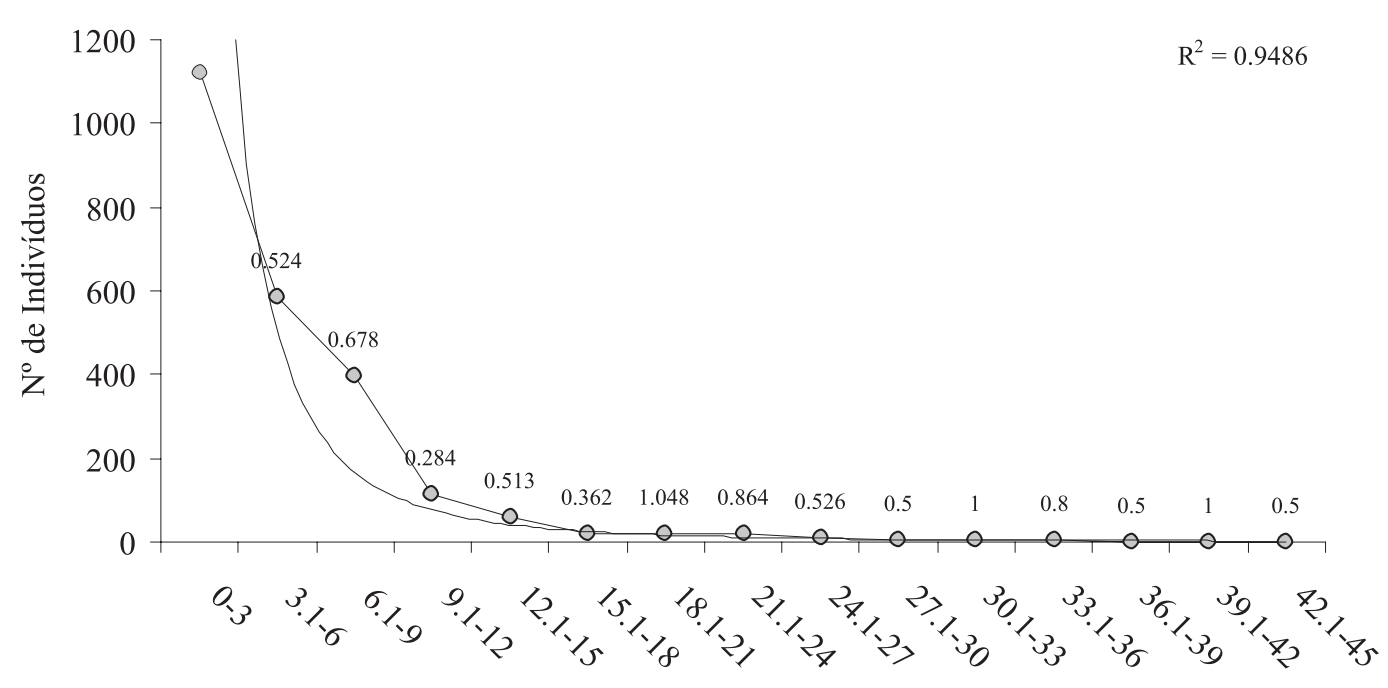

Classes de Diâmetro (cm) abundante, haja vista sua densidade de 1.347,5 indivíduos ha-1 ${ }^{-1}$ com 50,6\% do valor correspondente à classe de altura total; outros quatro táxons também apresentaram considerável valor de regeneração natural: Caesalpinia pyramidalis $(18,74)$, Jatropha mollissima $(12,87)$ e Cnidoscolus phyllacanthus $(6,31)$.

Estas espécies formam populações agregadas com grande número de indivíduos, compondo uma massa regenerante com altura máxima entorno dos $3 \mathrm{~m}$, com maior freqüência no intervalo de 0,30 a $1,5 \mathrm{~m}$ que corresponde às classes tamanho II e III.

De acordo com a distribuição diamétrica representada na Figura 1, observa-se a formação de uma curva exponencial, com "q" apresentando pequena variação entre as classes pareadas. A predominância de indivíduos nas primeiras classes de diâmetro demonstrou a elevada taxa de regeneração natural e de ingressados nos estádios ontogenéticos posteriores, o que sugere equilíbrio na sinúsia.

$\mathrm{Na}$ estratificação vertical da vegetação observase a predominância de indivíduos com altura de 0 a $3 \mathrm{~m}$ (Figura 2), o que corresponde a $84,46 \%$ dos espécimes. Este baixo porte apresentado se deve às sistemáticas supressões a que são submetidos os espécimes de maior porte.

Quanto à diversidade da vegetação, os valores de H'e E foram respectivamente de 1,962 e 0,635. Esses valores são inferiores aos obtidos por diversos autores em outras fisionomias de caatinga (Rodal et al. 1992, Rodal et al. 1998, Almeida \& Souza 1997, Pereira et al. 2002, Alcoforado-Filho et al. 2003).

Aliadas às condições de conservação da área,

Figura 1. Distribuição diamétrica da comunidade estudada e Quociente “q” de De Liocourt. Dados da Fazenda Madalena, município de Santa Luzia, PB. 


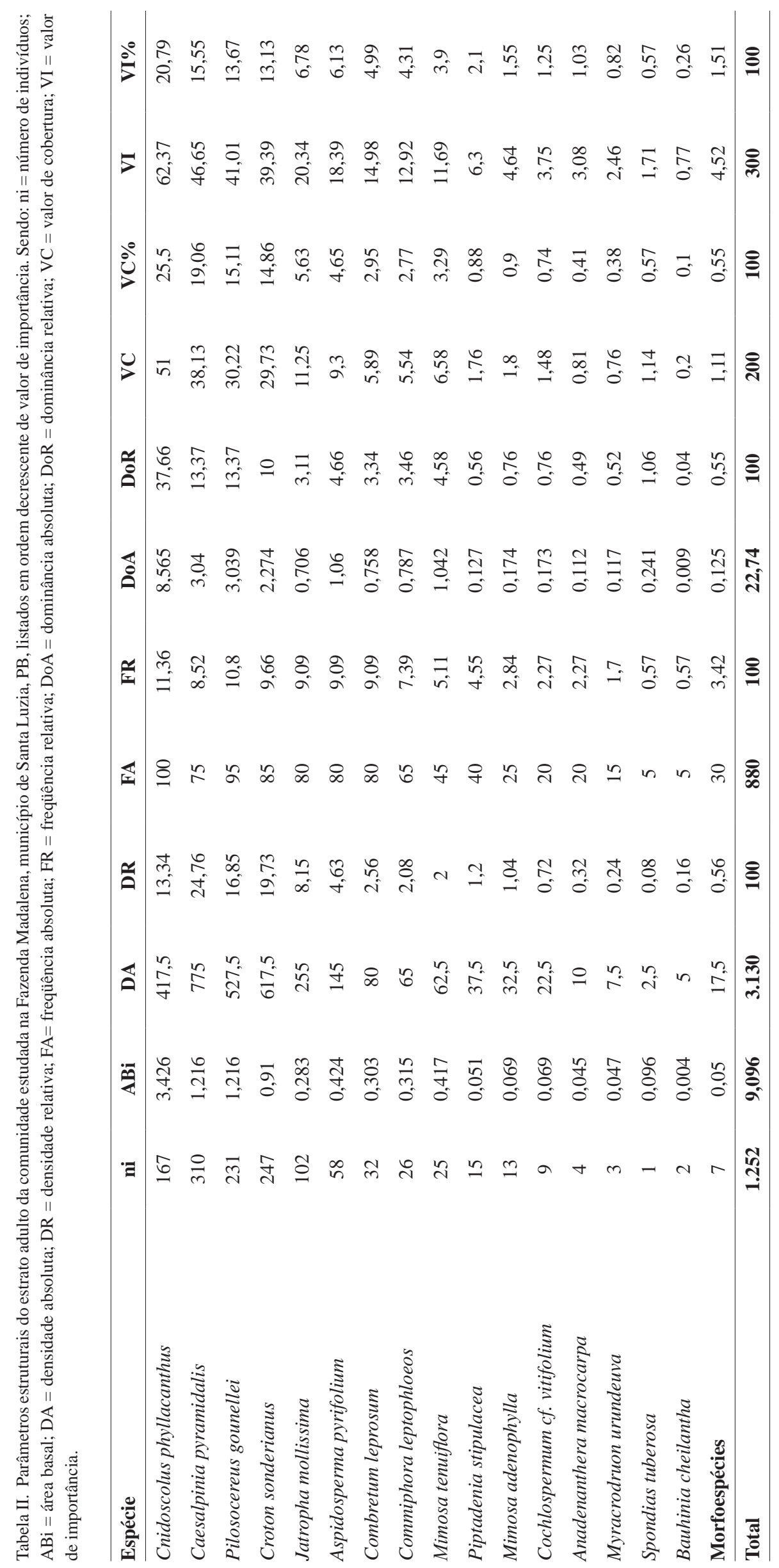




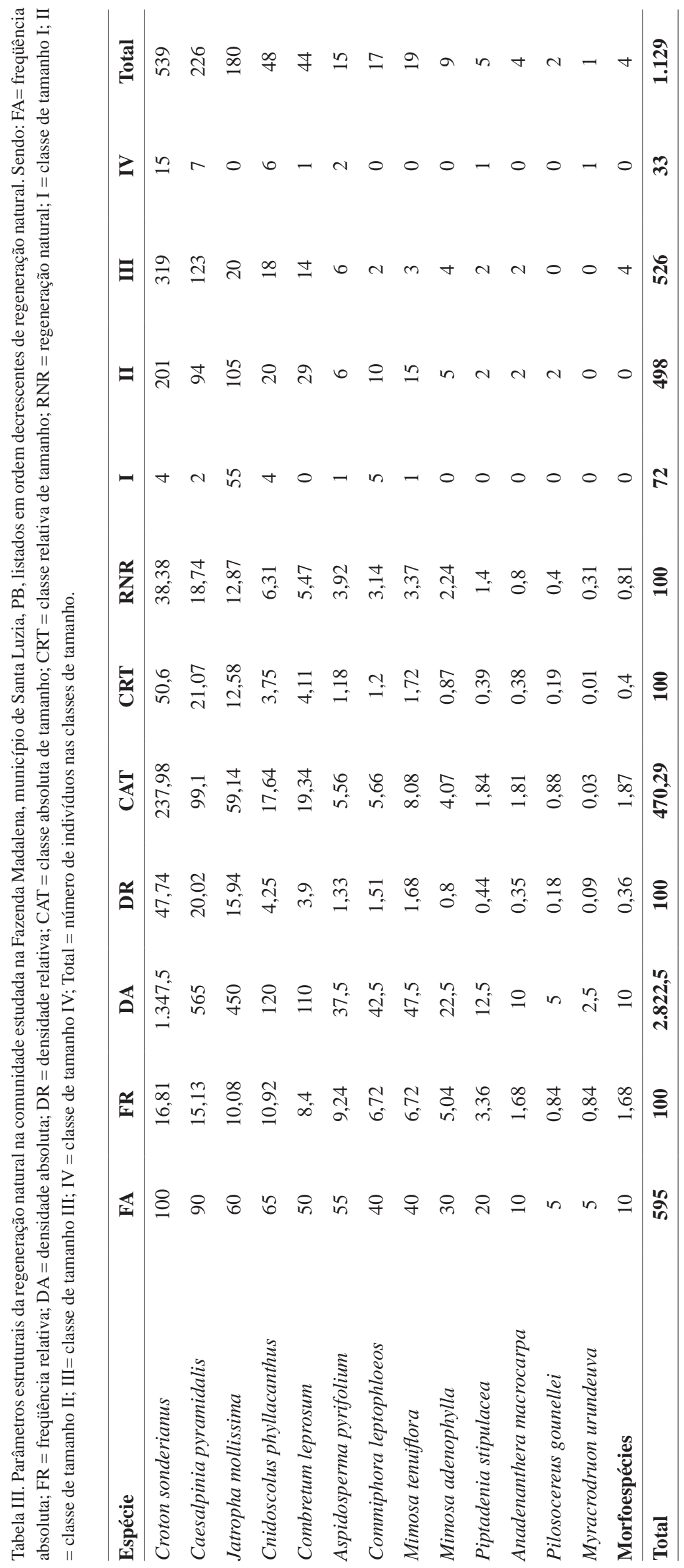




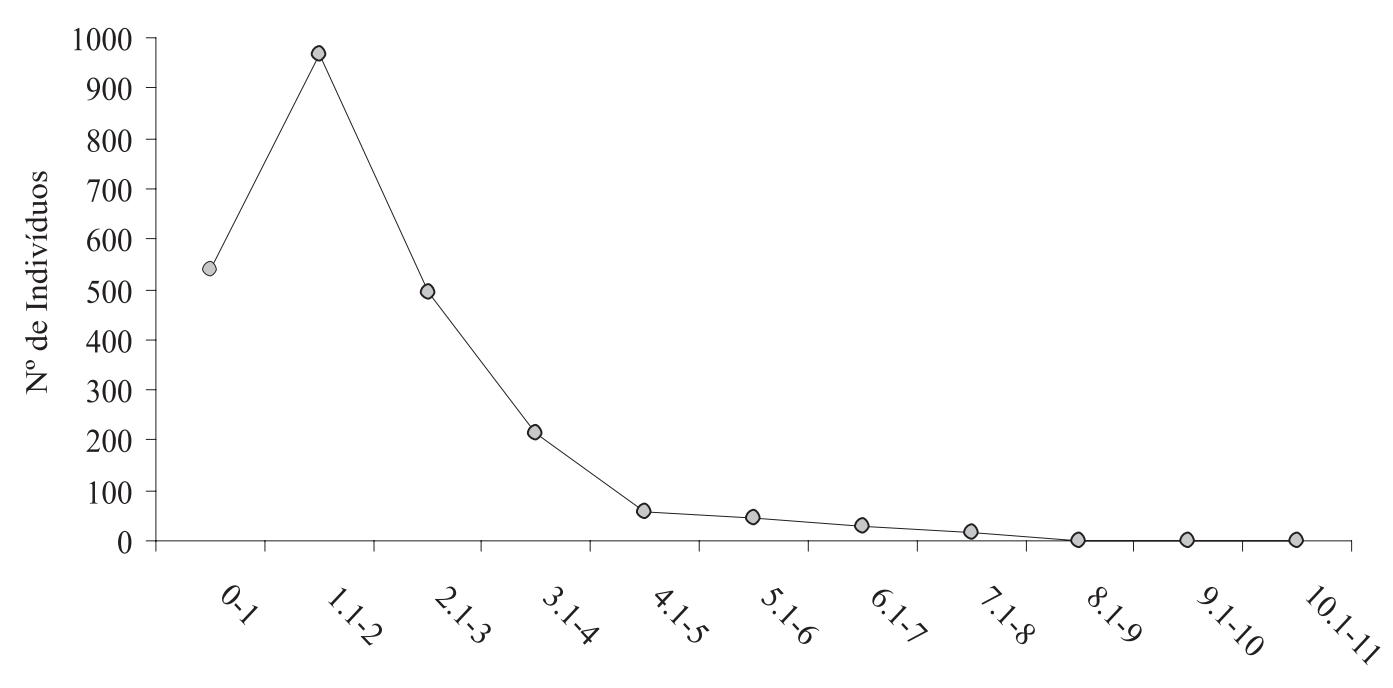

Classes de Altura (m)

Figura 2. Distribuição hipsométrica da comunidade estudada. Dados da Fazenda Madalena, município de Santa Luzia, PB.

concorrem para a baixa diversidade as limitações naturais da região, a exemplo de solos rasos e semiaridez acentuada, o que culmina na predominância de poucos táxons generalistas e na distribuição heterogênea da abundância dos indivíduos.

\section{CONSIDERAÇÕES FINAIS}

Nos $4.000 \mathrm{~m}^{2}$ deárea amostrada foraminventariados 2.368 indivíduos o que resulta em uma densidade de 5.920 indivíduos ha-1, tendo como espécies mais abundantes e importantes Croton sonderianus, Caesalpinia pyramidalis, Pilosocereus gounellei, Jatropha mollissima e Cnidoscolus phyllacanthus.

A despeito da baixa distribuição hipsométrica, constata-se um balanço equilibrado entre a mortalidade e o recrutamento dos indivíduos, o que caracteriza a comunidade como auto-regenerante.

Dominada por espécies típicas das fases inicial e intermediária do processo de sucessão ecológica, a comunidade apresenta baixa diversidade o que pode refletir, em parte, os impactos da exploração seletiva de lenha. Contudo, outros estudos já vêm mostrando que a baixa diversidade é uma característica marcante da vegetação do Seridó, quando comparada a outras fisionomias de caatinga.

AGRADECIMENTOS: Os autores agradecem ao Instituto Nacional do Semi-Árido (INSA) pelo fomento e ao proprietário da área estudada, Sr. Nilton Marinho, pela colaboração e apoio. O presente trabalho é parte da Dissertação de Mestrado do primeiro autor - bolsista CNPq.

\section{REFERÊNCIAS}

AGUIAR, J.T.E.; LACHER, J.R. \& DA SILVA, J.M.C. 2002. The Caatinga. Pp 174-181. In: R.A. Mittermeier, C.G. Mittermeier, P. Robles Gil, J. Pilgrim, G.A.B. Fonseca, T. Brooks \& W.R. Konstant, (eds.), Wilderness: earth’s last wild places. Cemex, Agrupación Serra Madre, S.C., México. 181p.

ALBUQUERQUE, U.P. \& ANDRADE, L.H.C. 2002. Conhecimento botânico tradicional e conservação em uma área de caatinga no estado de Pernambuco, nordeste do Brasil. Acta Botanica Brasilica, 16(3): 273-285.

ALCOFORADO-FILHO, F.G.; SAMPAIO, V.S.B. \& RODAL, M.J.N. 2003. Florística e fitossociologia de um remanescente de vegetação caducifólia espinhosa arbórea em Caruaru, Pernambuco. Acta Botanica Brasílica, 17(2): 287-303.

ALMEIDA, D.S. \& SOUZA, A.L. 1997. Florística e estrutura de um fragmento de floresta atlântica, no município de Juiz de Fora, MG. Revista Árvore, 21(2): 221-230.

AMORIM, I.L.; SAMPAIO, E.V.S.B. \& ARAUJO, E.L. 1995. Flora e estrutura da vegetação arbustivo-arbórea de uma área de caatinga do Seridó, RN, Brasil. Acta Botanica Brasílica, 19(3): 615-623.

ANDRADE, L.A.; REIS, M.G.F. \& REIS, G.G. 1999a. Classificação Ecológica do Estado da Paraíba. I. Interpolação de Dados Climáticos por Aproximação Numérica. Revista Árvore, 23(1): 3-32.

ANDRADE, L.A.; REIS, M.G.F.; REIS, G.G. \& SOUZA, A.L. 1999b. Classificação ecológica do Estado da Paraíba 2. Delimitção e caracterização de regiões ecológicas a partir de variáveis climáticas. Revista Árvore, 23(2): 139-149. 
ANDRADE, L.A.; PEREIRA, I.M.; LEITE, U.T. \& BARBOSA, M.R.V. 2005. Análise da cobertura de duas fitofisionomias de caatinga, com diferentes históricos de uso, no município de São João do Cariri, estado da Paraíba. Cerne, 11(3): 253262.

ANDRADE-LIMA, D. 1981. The Caatingas Dominium. Revista Braileira de Botânica, 4: 149-153.

APG (ANGIOSPERM PHYLOGENY GROUP). 2003. An update of the Angiosperm Phylogeny Group classification for the orders and families of flowering plants: APG II. Botanical Journal of the Linnean Society: 141: 399-436.

ARAÚJO, E.L.; SAMPAIO, E.V.S.B. \& RODAL, M.J.N. 1995. Composição florística e fitossociológica de três áreas de caatinga. Revista Brasileira de Biologia, 55(4): 595-607.

ARAUJO, F.S. \& MARTINS, F.R. 1999. Fisionomia e organização da vegetação do carrasco no planalto da Ibiapaba, Estado do Ceará. Acta Botanica Brasílica, 13(1): 1-13.

BROWN-BLANQUET, J. 1950. Sociologia vegetal: estudio de las comunidades vegetales. Acme, Buenos Áries. 44p.

BRUMMITT, R.K. \& POWELL, C.E. 1992. Authors of plant names. Royal Botanic Gardens. New York. 732p.

DRUMOND, M.A.; KIILL, L.H.P. \& NASCIMENTO, C.E.S. 2002. Inventário e sociabilidade de espécies arbóreas e arbustiva da Caatinga na Região de Petrolina, PE. Brasil Florestal, 74: 37-43.

ENGLER, W.A. 1951. Contribuição ao estudo da caatinga pernambucana. Revista Brasileira de Geografia, 13: 51-63.

FERRAZ, E.M.N.; RODAL, M.J.N.; SAMPAIO, E.V.S.B. \& PEREIRA, R.C.A. 1998. Composição florística em trechos de vegetação de caatinga e brejo de altitude na região do Vale do Pajeú, Pernambuco. Revista Brasileira de Botânica, 21(1): 7-15.

FERREIRA, R. 1988. Análise estrutural da vegetação da Estação Florestal de Experimentação de Açú - RN, como subsídio básico para o manejo florestal. Dissertação de Mestrado. Universidade Federal de Viçosa, Viçosa. 98p.

FIGUEIREDO, M.A. 1987. A microrregião salineira norteriograndenseno domínio das caatingas (Coleção Mossoroense 353). Escola Superior de Agricultura de Mossoró, Mossoró. $44 \mathrm{p}$.

IBGE (FUNDAÇÃO INSTITUTO BRASILEIRO DE GEOGRAFIA E ESTATISTICA). 2006. Mapa de solos do Brasil: http://mapas.ibge.gov.br/website/solos/viewer.htm. (acesso em 22/05/2006).

KENT, M. \& COKER, P. 1999. Vegetation Description and Analysis - a pratical approach. John Wiley \& Sons, Chichester. 363p.
LAMPRECHT, H. 1964. Ensayo sobre la estructura floristica de la parte Sur-Oriental del bosque universitario: El Caimital, Estado Barinas. Revista Florestal Venezuelana, 7(10/11): 77119.

LEAL, I.R.; TABARELLI, M. \& SILVA, J.M.C. 2003. Ecologia e conservação da Caatinga. Editora Universitária, Universidade Federal de Pernambuco, Recife, Brasil. 822p.

LEMOS, J.R. \& RODAL, M.J.N. 2002. Fitossociologia do componente lenhoso de um trecho da vegetação de caatinga no parque nacional serra de capivara, Piauí, Brasil. Acta Botanica Brasilica,16(1): 23-42.

MATEUCCI, S.D. \& COLMA, A. 1982. Metodologia para el estudio de la vegetacion. Programa Regional de Desarrolo Científico y Tecnológico, Washington. 168p.

MMA(MINISTÉRIO DO MEIO AMBIENTE, DOS RECURSOS HÍDRICOS E DA AMAZÔNIA LEGAL). 2002. Avaliação e ações prioritárias para a conservação da biodiversidade da caatinga. Universidade Federal de Pernambuco/Fundação de apoio ao desenvolvimento, Fundação Biosiversitas, EMBRAPA/Semi-Árido, MMA/SBF, Brasília - DF. 36p.

MULLER - DOMBOIS, D. \& ELLEMBERG, H. 1974. Aims and methods of vegetation ecology. John Wiley \& Sons, New York. 547p.

ODUM, E.P. 1988. Ecologia. Guanabara, Rio de Janeiro. 434p.

OLIVEIRA, M.E.A.; SAMPAIO, E.V.S.B.; CASTRO, A.A.J.F. \& RODAL, M.J.N. 1997. Flora e fitossociologia de uma área de transição carrasco-caatinga de areia em Padre Marcos, Piauí. Naturalia, 2: 131-150.

PEREIRA, I.M.; ANDRADE, L.A.; COSTA, J.R.M. \& DIAS, J.M. 2001. Regeneração Natural em um remanescente de caatinga sob diferentes níveis de perpetuação, no Agreste paraibano. Acta Botanica Brasilica,15(3): 413-426.

PEREIRA, I.M.; ANDRADE, L.A.; BARBOSA, M.R.V. \& SAMPAIO, E.V.S.B. 2002. Composição florística e análise fitossociológica do componente arbustivo-arbóreo de um remanescente florestal no Agreste Paraibano. Acta Botanica Brasilica,16(3): 241-369.

RICKLEFS, R.E. 1996. A economia da natureza. Guanabara Koogan, Rio de Janeiro. 470p.

RIZZINI, C.T. 1997. Tratado de fitogeografia do Brasil (Segunda Edição). Âmbito Cultural Edições Ltda., Rio de Janeiro. 157p.

RODAL, M.J.N. \& NASCIMENTO, L.M. 2002. Levantamento florístico da floresta serrana da reserva biológica de Serra Negra, microrregião de Itaparica, Pernambuco, Brasil. Acta Botanica Brasilica,16(4): 481-500.

RODAL, M.J.N.F; SAMPAIO, E.V.S.B. \& FIGUEIREDO, M.A. 1992. Manual sobre métodos de estudos florísticos e 
fitossociológicos - ecossistema caatinga. Sociedade Botânica do Brasil, Brasília. 32p.

RODAL, M.J.N.; ANDRADE, K.V. de A.; SALES, M.F. \& GOMES, A.P.S. 1998. Fitossociologia do componente lenhoso de um refúgio vegetacional no município de Buíque, Pernambuco. Revista Brasileira de Biologia, 58(3): 517-526. SAMPAIO, E.V.S.B. 1996. Fitossociologia. Pp: 203-224. In: E.V.S.B. Sampaio; S.J. Mayo \& M. R.V. Barbossa, (eds.), Pesquisa Botânica do Nordeste: Progresso e perspectivas. Sociedade Botânica do Brasil, Recife. 224p.

SAMPAIO, E.V.S.B.; ARAÚJO, E.L. DE.; SALCEDO, I. H. \& TIESSEN, H. 1998. Regeneração da vegetação de Caatinga após corte e queima, em Serra Talhada, PE. Pesquisa Agropecuária Brasileira, 33(5): 621-632.

SCOLFORO, J.R.S.; PULZ, F.A. \& MELLO, J.M. 1998. Modelagem da produção, idade das florestas nativas, distribuição espacial das espécies e a análise estrutural. Pp 189-245. In: J.R.S. Scolforo, (org.), Manejo Florestal. UFLA/ FAEPE, Lavras. 245p.

TABARELLI, M.; SILVA, J.M.C.; SANTOS, A.M.M. \& VICENTE, A. 2000. Análise de representatividade das unidades de conservação de uso direto e indireto na caatinga. Relatório do Projeto Avaliação e Ações Prioritárias para a Conservação da biodiversidade da Caatinga, Petrolina, Brasil. The Nature Conservancy do Brasil \& Associação Caatinga, Recife. 301p.

TAVARES, S.; PAIVA, F.A.V.; TAVARES, E.J.S. \& CARVALHO, G.H. 1975. Inventário florestal da Paraiba e no Rio Grande do Norte l. Estudo preliminar das matas remanescentes do vale do Piranhas (Recursos Naturais 3). SUDENE, Recife. p.15-31.

WADSWORTH, F.H. 2000. Producción forestal para América Tropical. USDA, Washington, USA. 602p.

WHITTAKER, R.H. 1984. Classification of Plant Communities. Kluwer Academic Publishers Group, Boston. 408p.

Submetido em 18/10/2007.

Aceito em 09/12/2007. 